\title{
HOMOMORPHSIM OF T-FUZZY SOFT NORMAL IDEALS OF RING
}

\author{
ANITHA $\mathrm{N}^{1}$ and latha $\mathrm{s}^{1}$ \\ ${ }^{1}$ Periyar University
}

May 15, 2020

\begin{abstract}
In this paper, we characterize T-soft ideals,T-fuzzy soft normal ideals over a ring and give a portion of their properties. Likewise, we present homomorphism, hostile to homomorphism, isomorphism and anti- isomorphism of T-fuzzy soft normalideals ordinary standards over the ring. In addition, we show that the image and preimage of homomorphism, hostile to homomorphism, isomorphism and against isomorphism of T-fuzzysoft normal ideals over the ring under certain conditions.
\end{abstract}

\section{Hosted file}

homomorphism T-fuzzy ideal new.pdf available at https://authorea.com/users/322534/articles/ 451478-homomorphsim-of-t-fuzzy-soft-normal-ideals-of-ring 